\title{
LA MEDIACIÓN INTERCULTURAL EN LAS ASOCIACIONES DE INMIGRANTES DE ORIGEN AFRICANO
}

\section{INTERCULTURAL MEDIATION IN THE ASSOCIATIONS OF AFRICAN ORIGIN}

\author{
Núria Llevot CALvet nllevot@pip.udl.cat \\ Universidad de Lérida. España \\ JoRDI GARRETA BoCHACA jgarreta@geosoc.udl.cat \\ Universidad de Lérida. España
}

\begin{abstract}
RESUMEN
El artículo analiza cómo realizan la mediación intercultural las asociaciones de inmigrantes de origen africano de tres comunidades autónomas (Cataluña, Valencia y Navarra) y qué caracteriza a sus actores. El análisis se basa en una encuesta realizada a 206 asociaciones de inmigrantes y en 30 entrevistas: 15 a directivos, 10 a administraciones y entidades que trabajan con ellas, y 5 a inmigrantes no asociados. Los resultados apuntan a que las asociaciones son espacios de convivencia, pero una parte importante de ellas carece de objetivos específicos claros en sus planteamientos de trabajo con sus usuarios y otros agentes sociales. También hemos visto que la mediación es una práctica incipiente en las asociaciones, al contrario de lo que sucede en el seno de las instituciones españolas del ámbito educativo, sanitario y familiar. Por otra parte, hemos apreciado que las asociaciones africanas desvirtúan, a menudo, el concepto de mediación considerándola simplemente como una conversación entre los suyos.
\end{abstract}

\section{Palabras Clave}

Asociaciones; Inmigrante africano; Mediación intercultural; Mediación natural; Mediación profesional.

\section{Abstract}

The article presents an analysis of intercultural mediation in the associations of African-origin immigrants in three regions (Catalonia, Valencia and Navarre). Specifically, we present how this is being carried out together with the situation of the mediators based on a survey of 206 associations of immigrant-origin people and thirty interviews (fifteen with managers; ten with administrations and entities that habitually work with these associations and five with non-associated immigrants). The results indicate that the associations are place of coexistence, but a significant proportion of these lack specific clear objectives in their work with their users and other social agents. This practice in the associations is incipient, in contrast with the trend in the Spanish entities, witch now are beginning to apply this in the educational, health and family environments. Furthermore, the African associations often distort this concept considering it simply as a conversation among their own people.

\section{KEYWORDS}

Associations; African-Origin Immigrant; Intercultural Mediation; Voluntary and Professional Work. 


\section{LA MEDIACIÓN}

Desde el siglo XIII se utiliza la palabra "mediación" para designar la acción de intervenir entre dos personas o grupos. Esta intervención podía darse para terciar entre vecinos que discutían por la propiedad de unas tierras, entre familias que trataban de concertar un matrimonio o repartir una herencia, o bien entre víctimas y personas que habían cometido algún delito y trataban de dictaminar sobre quién recaía la culpa. El mediador ${ }^{1}$ era considerado como tal por sus convecinos debido a su prudencia, responsabilidad y sabiduría, razones por las que estos le otorgaban su confianza.

A lo largo de los siglos, algunas culturas han tenido personas que, en los clanes, tribus y pueblos, han ejercido de mediadoras. Como ejemplo cercano conocemos el poder que se le otorga al patriarca en la cultura gitana o el que se le concedía, en algunos pueblos de España, al párroco o al maestro, aparte del poder oficial que representaba el juez de paz. Todos estos individuos eran los miembros que la comunidad consideraba más juiciosos y justos para intervenir en disputas de vecindad o de familias.

En trabajos propios (Llevot 2006; 2011) centrados en el análisis de la mediación intercultural que se realiza con y entre personas de origen inmigrante, hemos podido extraer algunas conclusiones sobre el papel que las personas involucradas en estos procesos realizan de forma voluntaria y espontánea, lo que podría englobarse en lo que se ha llamado "mediación natural o informal". Esta suele realizarse entre personas que se tienen confianza, en condiciones de solidaridad y que no acostumbra a traspasar los límites de lo personal/familiar o del boca a boca. Así, observamos que, en los momentos iniciales de la llegada de un inmigrante, las amistades y la familia son los eslabones primarios, los que generalmente le facilitan vivienda de manera provisional y le sirven de intérpretes. El colectivo de ayuda y de mediación, dependiendo de las situaciones concretas, puede proceder, también, de la comunidad local o regional de origen, de asociaciones nacionales, de redes informales de relaciones y de otras instancias que intercambian, de manera natural, recursos y oportunidades.

"La acción mediadora o mediación espontánea puede producirse esporádicamente 0 de forma circunscrita a un determinado círculo de amistades o de relaciones familiares, por ejemplo, dando acogida a los nuevos miembros de un grupo que llegan al país 0 a aquellos que, pese al tiempo transcurrido, mantienen déficit en la adquisición de las lenguas vehiculares. Puede incluirse entre quienes ejercen acciones mediadoras a los menores que operan como traductores o mensajeros y a las personas que, por la anti-

El trabajo que se presenta es el resultado del proyecto de investigación "Asociacionismo e inmigración africana: funciones latentes y manifiestas" financiado por el Ministerio de Ciencia e Innovación (CSO20080122/SOCl).

${ }^{1}$ Para facilitar la lectura del artículo hemos utilizado los conceptos mediadores, entrevistados, etc. en un sentido neutro, refiriéndonos simultáneamente al género masculino y al femenino. Siempre que ha sido necesaria una mayor concreción esta se ha realizado. 
güedad de su asentamiento, pueden ayudar dentro del círculo mencionado a gestionar los vínculos institucionales brindando informaciones y/o acompañamientos, facilitando la inclusión al ofrecer vivienda y trabajo. Este tipo de acciones suelen establecerse en el intercambio que se produce dentro de relaciones primarias y redes sociales de 'paisanos' y se vinculan con el desarrollo de la ayuda mutua" (Jabbaz y Moncusí 2010: 191).

Utilizando un símil, podríamos decir que este tipo de actuaciones son como un apagafuegos: útiles en contextos concretos o en situaciones de emergencia, válidas a través de todo el itinerario vital de las sociedades y utilizadas cada vez más por profesionales que depositan su confianza en alguna persona que, por sus características, se la gana, pero son de relativa utilidad en casos delicados o de conflicto, así como en situaciones que responden a una lógica de cambio y adaptación exigida por la convivencia intercultural (Cohen-Emerique y Fayman 2005). En cambio, lo que se denomina, en el ámbito de las ciencias sociales, "mediación intercultural" presupone una cierta especialización o profesionalización de los actores y un reconocimiento de su papel más allá de las redes de sociabilidad y parentesco (Llevot 2011).

\section{LA MEDIACIÓN INTERCULTURAL. HACIA UNA DEFINICIÓN}

La naturaleza de la mediación como intervención de terceros para apoyar a partes involucradas en conflictos se hace más compleja cuando se incorpora la variante cultural: cultura de las partes, cultura del mediador, influencia de los factores culturales en la relación, contenido del conflicto, etc.

Para comprender más profundamente el término "mediación" en relación con sus diversas prácticas, seguiremos a Margalit Cohen-Emerique (2011), que distingue tres significados:

- El primero se refiere a la facilitación de la comunicación y comprensión entre personas de culturas diferentes en situaciones en las que no existe conflicto sino, más bien, una dificultad comunicativa. Se habla entonces de hacer "mediación preventiva", en la que un tercero restablece la comunicación entre las partes.

- Una segunda acepción la define como una intervención destinada a poner de acuerdo, conciliar o reconciliar a personas o partes. Este significado nos remite a una situación de conflicto, oposición o antagonismo que hace necesaria la intervención de un tercero. Se trata de la "mediación rehabilitadora", que interviene en la regulación y gestión de conflictos y tensiones interculturales.

- Por último, la tercera definición considera la mediación como un proceso creador por el cual se pasa, de un estadio inicial, a un determinado final. En este caso se da una transformación en la que el mediador se convierte en el catalizador de un proceso dinámico activo (superando las normas, costumbres y puntos de vista particulares), dado en situaciones de convivencia multicultural, que culmina con el establecimiento de nuevas normas y modos de relación compartidos. Es la "mediación creativa". 
Las funciones de estas personas mediadoras interculturales son: facilitar la inserción, crear vínculos y redes sociales, mediar en conflictos cuando estos se producen, sensibilizar a la sociedad mayoritaria, etc. La espontaneidad solidaria necesita la compañía de profesionales formados que ayuden en la reflexión y en la mediación ya que son portadores de técnicas y habilidades esenciales en determinadas situaciones.

La "mediación formal" propiamente dicha sirve, pues, para disipar los malentendidos y resentimientos ligados a dos tipos de causas (Cohen-Emerique 1999):

- La primera es el desconocimiento de los códigos y valores respectivos, lo cual es una fuente de malas interpretaciones y de incomprensiones y, por ello, la causa de que las acciones llevadas a cabo por parte de los agentes de integración resulten ineficaces. En estos casos, la función del mediador consiste en dar sentido a los valores y comportamientos del otro diferente, un sentido que va a disipar los malentendidos en la interacción y las representaciones negativas que los agentes institucionales puedan tener hacia el inmigrante. De este modo, el mediador es un facilitador, no solo de la comunicación, sino también del respeto mutuo entre ambas partes.

- La segunda causa de malentendidos estriba en los prejuicios y en las representaciones negativas de los agentes institucionales hacia el inmigrante, los cuales engendran una dinámica identitaria en la que siempre están en juego las diferencias de estatus ligadas a la historia, lo político y lo económico (Abdallah-Pretceille 1986). Esta dinámica siempre entraña una relación dominantedominado, mayoritario-minoritario, desarrollado-subdesarrollado, etc., en la que el inmigrante suele estar en posición de inferioridad y desvalorización. En este caso, el papel del mediador consistirá en disipar estas imágenes negativas del profesional que le llevan a minusvalorar al inmigrante.

Los conflictos interculturales surgen en diversos contextos (Camilleri y CohenEmerique 1989): bien entre la sociedad de acogida y los inmigrantes, a propósito de cuestiones relativas a la salud (como ciertas pruebas médicas rechazadas por determinados pacientes) o relativas a la educación (como el velo islámico en la escuela, los niños maltratados, el concepto de escuela y el rol del maestro, etc.); bien en el seno de familias afectadas por procesos de aculturación o atrapadas en difíciles situaciones de adaptación, fuente de conflictos entre padres e hijos (como la transgresión del código de honor tradicional por parte de las hijas, el matrimonio forzado, la falta de respeto, etc.). El mediador también puede convertirse en un agente de cambio para emprender acciones innovadoras que no solo no estaban previstas al principio de la intervención sino que no tenían ninguna relación con la misión institucional. Esta mediación crítica no constituye una tarea fácil para los mediadores, sobre todo porque implica un diálogo crítico con las instituciones y porque muchos profesionales son reacios a cambiar sus dinámicas y, en consecuencia, minimizan o rechazan la mediación propiamente dicha. 


\section{LA PRÁCTICA DE LA MEDIACIÓN INTERCULTURAL EN ESPAÑA}

La mediación intercultural ha ido surgiendo en España ante la realidad social pluricultural y transcultural con la que nos hemos ido encontrando. En su desarrollo podemos distinguir tres etapas (Richarte y Díe 2008), a las que nosotros añadimos una cuarta:

- Una primera etapa, de origen o génesis, que va de 1994 a 1997, en la que la mediación intercultural surge como práctica al producirse intervenciones entre personas de diferentes culturas (especialmente entre personas pertenecientes a minorías étnicas y personas de otros países), casi de forma espontánea y porque la realidad afluente lo va exigiendo.

- Una segunda fase, de despliegue o desarrollo, que se sitúa entre los años 1998 y 2002, cuando la práctica realizada y la experiencia acumulada en temas de mediación intercultural comienza a ser abundante y significativa y se empieza a hacer un estudio, tal vez más teórico de lo que realmente tenía que haber sido, de la situación; se crean más proyectos de mediación intercultural; se forma el Grupo Triángulo (federación de varias entidades que trabajan temas de mediación entre culturas); las universidades comienzan a incluir en sus programas, cursos y postgrados la especialidad de mediación intercultural; y se realiza el Primer Congreso Internacional de Mediación Intercultural.

- La etapa del boom o expansión, que se sitúa entre los años 2003 y 2007. En esta tercera fase se da una proliferación de programas municipales de mediación intercultural, se diseñan los planes de integración social en materia de inmigración y surge la figura del agente de mediación intercultural en casi todas las comunidades autónomas. Parece que el despliegue de esta disciplina es ya imparable y se insiste en que sea reconocida como profesión.

- La etapa de retroceso, que se sitúa entre 2008 y 2012. A pesar del tiempo transcurrido desde los primeros programas de mediación, esta continúa en una situación de precariedad y de gran diversidad en cuanto a entidades o instituciones que se dedican a este campo y en cuanto a formas de entender la práctica profesional por parte de todos los implicados. Esto se traduce en la ausencia de una cualificación profesional consensuada y reconocida, a lo que se añade una formación inadecuada de los mediadores. Además, debido a la crisis económica general, se recortan e, incluso, se cierran los programas y las subvenciones dedicadas a la mediación y a la participación de mediadores en proyectos europeos transnacionales.

En la actualidad, la figura del mediador intercultural se ejerce desde, al menos, cuatro modelos diferentes, según la institución u organización a la que pertenece cada 
individuo (AEP Desenvolupament Comunitari o Andalucía Acoge 2002; Martínez Usarralde y García López 2009), que tienen unas evidentes consecuencias en el resultado de la mediación: el modelo asociativo, el modelo institucional, el modelo cooperativo y el modelo autónomo.

- El modelo asociativo es, quizás, el más desarrollado pero también el más informal y desregularizado. Aquí el mediador interviene desde asociaciones u organizaciones que trabajan con colectivos de inmigrantes o que pertenecen a minorías étnicas. Es, en este contexto, en el que se ha ido desarrollando el perfil profesional del mediador hasta convertirse en una figura necesaria: se trata de alguien que pertenece al colectivo minoritario, que ha ejercido la mediación, básicamente por razones de comunicación lingüística, y, en una primera instancia, de manera instintiva, sin una formación previa.

- El modelo institucional surge a partir de la demanda de profesionales, por parte de las instituciones públicas (que son las prestadoras de servicios educativos, sanitarios y sociales), para atender a los usuarios llegados de otros países, ya que estos hablan otras lenguas y tienen otras costumbres. La llegada de inmigrantes lleva a las instituciones a tomar medidas y a generar figuras mediadoras que puedan satisfacer las diferentes necesidades de estos colectivos y que sean capaces de generar proyectos y formaciones transnacionales. Todas estas actuaciones se realizan casi siempre con recursos bastante escasos.

- El modelo cooperativo cristaliza en entidades privadas, prestadoras de servicios de mediación bajo diferentes formas jurídicas. Ejemplificaremos tres de ellas: en España, la iniciativa "Solomediación", de Olot (Gerona), que parte de un portal de la mediación (Acord.sc); en Finlandia, "Grebe Consult", que permite, también, trabajar la mediación y la resolución de conflictos a una escala más global; y, por último, en Estados Unidos, "Oregon Mediation Center", que ofrece a la comunidad virtual la posibilidad de acceder y localizar mediadores y proyectos en red.

- El modelo autónomo, que es el que sigue el profesional de la mediación que ejerce su trabajo libremente. Lo ideal sería contar con un Colegio Profesional que legitimase y salvaguardase esta figura, que fijase sus competencias profesionales y la protegiese frente al posible peligro de intrusismo. Este modelo carece del necesario referente colectivo y multicultural; lo apuntamos, únicamente, como una posibilidad más dentro de la práctica de la mediación y como un elemento a aportar al debate sobre su futura profesionalización. 


\section{LAS ASOCIACIONES AFRICANAS DE INMIGRANTES Y LA MEDIACIÓN INTERCULTURAL}

Los objetivos que han instruido este trabajo han sido: el análisis del tipo de mediación que se realiza desde las asociaciones africanas y la descripción de la situación de sus mediadores. Para ello hemos utilizado tanto metodología cuantitativa, como cualitativa. Nuestro punto de partida fue una encuesta realizada a 206 asociaciones de africanos y 30 entrevistas en profundidad a todos los miembros del total de las asociaciones, que declaraban ejercer la mediación intercultural, así como a sus interlocutores habituales. Hicimos 15 entrevistas a directivos de asociaciones africanas de inmigrantes (7, en Cataluña; 5 , en Valencia; $y 3$, en Navarra); 10 a profesionales de administraciones y entidades que trabajan habitualmente con estas asociaciones (1, en Cataluña; 8 , en Valencia; y 1 , en Navarra); y 5 entrevistas, también, a inmigrantes no asociados (todos de Valencia) ${ }^{2}$. A continuación expondremos los resultados de la fase cuantitativa y cualitativa.

Los resultados de la encuesta, realizada a 206 representantes de asociaciones de personas de origen africano de Cataluña, Comunidad Valenciana y Navarra, indican que una de sus actividades más habituales es la mediación intercultural; concretamente, el $43,2 \%$ afirma que lleva a cabo proyectos de mediación de forma espontánea. Por lo que se refiere a otras actividades: el 30,6\% realiza sesiones de sensibilización externa; el $26,7 \%$, proyectos de codesarrollo3; el 22,8\%, proyectos de inserción laboral; el 22,8\%, formación en lengua castellana para mujeres; y, el 21,4\%, formación para hombres (ver Garreta y Llevot 2013). Si diferenciamos la muestra internamente, podemos observar que la mediación se ha desarrollado más en Cataluña - donde el 49,3\% de las asociaciones está llevando a cabo proyectos de este tipo- que en la Comunidad Valenciana $(35,2 \%)$ o en Navarra $(14,3 \%)$.

Otra de las variables que la muestra distingue de forma significativa es el año de creación de la asociación; así, tenemos que las de más reciente creación realizan este tipo de actividad mucho menos (el $27,1 \%$ de las creadas en los últimos tres años) que las más antiguas (el $84,6 \%$ de las que fueron creadas hace más de 19 años). Eso sí, entre estas fechas existe un cierto incremento, aunque no lineal, de esta dedicación.

Al mismo tiempo, de acuerdo con los clusters construidos por el equipo de investigación (ver la clasificación de Garreta y Llevot 2013), hallamos que la mediación se desarrolla más en las asociaciones que hemos llamado "voluntaristas reticulares" $(60,5 \%)$ y en las "profesionalizadas" $(45,5 \%)$, ya que se trata de las asociaciones con mayor proyección exterior, mientras que se reduce entre las "voluntaristas de base" $(37,9 \%)$ y las "voluntaristas estructuradas" (38,6\%).

Por otro lado, cuando se pregunta sobre las actividades que les habría gustado

\footnotetext{
${ }^{2}$ Para conocer en profundidad la metodología de investigación es imprescindible consultar la introducción metodológica al monográfico "Asociacionismo e inmigración" de la Revista Internacional de Sociología donde se halla este artículo.

${ }^{3}$ De estos resultados, cabría preguntarse en qué medida la mediación y el codesarrollo responden a una iniciativa propia o bien se deben a la presión del entorno, cuestión que abordaremos en las reflexiones.
} 
realizar, el 4,9\% menciona la mediación. Así que esta no es la respuesta más frecuente sino que está por detrás de otras actividades como: cursos de lengua (13,1\%, enseñanza de castellano para mujeres; $12,1 \%$, para hombres; $11,7 \%$, catalán para mujeres; $\mathrm{y} 11,2 \%$, para hombres), proyectos de inserción laboral (6,8\%) y proyectos de codesarrollo (6,8\%). De nuevo es en Cataluña $(5,8 \%)$ donde más se menciona esta actividad, seguida de la Comunidad Valenciana (3,7\%) y no mencionada en Navarra.

La fase cualitativa, basada en las citadas entrevistas, nos ha permitido profundizar en la práctica de lamediación intercultural que se realizadesde las asociaciones africanas ubicadas en las citadas comunidades autónomas. Comparativamente, tal como avanzábamos en la encuesta, en Cataluña y en Valencia existe más tradición en experiencias de mediación, sobre todo en programas europeos e iniciativas comunitarias (ADEMV10).

Mayoritariamente se da la coincidencia de que los mediadores son los presidentes o los responsables de las asociaciones y provienen de países como Senegal, Marruecos, Gambia, Burkina Faso, Mali y Guinea-Bissau. Respecto a la distinción por géneros, como muestra la encuesta, la mediación se lleva a cabo por igual, tanto en las asociaciones formadas solo por hombres (33\%), como en las asociaciones formadas principalmente por hombres (44\%). Así, para las mujeres, la mediación intercultural tiene un significado especial, pues las entrevistadas apuestan por la inserción laboral de la mujer para romper las tradiciones propias de su género, atribuidas, habitualmente, a la religión musulmana, de la que dicen que "atrasa la emancipación femenina" (ADEMV10). Por ello, tanto el modelo de mediadora como el de trabajadora (con cierto estatus dentro del colectivo minoritario) sería un referente válido para otras mujeres musulmanas, ya que, a menudo, sus opciones son limitadas y, como afirman, o se quedan en casa, o solo encuentran trabajo en el servicio doméstico.

En las asociaciones formadas por mujeres (el $63,6 \%$ de las formadas principalmente por mujeres y el $30 \%$ de las que solo están formadas por mujeres) se habla de los problemas personales y profesionales que tienen en la sociedad de acogida. Para superarlos desarrollan proyectos de mediación en las asociaciones y una parte de las demandas que satisfacen procede de ellas. De hecho, si observamos bien un fenómeno al que hemos denominado la "feminización de la mediación", sobre el que sería necesario profundizar más, también se observa un incremento del número de socias, y así nos lo indican las entrevistas a mujeres mediadoras. Es evidente que no es objeto del presente trabajo pero también hay que señalar que, en las informaciones recogidas a lo largo del mismo -y sobre todo en la parte cualitativa-, aparecen una serie de afirmaciones que nos enfrentan a la curiosa contradicción de que diferencias que no existen en cuestión de origen geográfico, étnico o cultural, sí aparecen en cuanto al género. Además, todos los entrevistados (hombres y mujeres) hacen una valoración muy buena de la actitud de las mujeres y de sus capacidades para la mediación. Aquí sí se produce un claro proceso de discriminación positiva. Existe una corriente de empatía que visualiza a la mujer inmigrante de una forma diferente, con una problemática más afín a la imagen profesional del "autóctono" (NMMV10). La mediación contribuiría al empoderamiento 
de la mujer frente a los hombres y ante el resto de la sociedad (ver Moncusí y Albert 2013), constituyéndose, pues, el nacimiento de una categoría de extranjeras dinámicas y fuertemente integradas (EEMC10, AMAMT10I). El enlace entre identidad e integración dependerá, en gran parte, de la capacidad de la sociedad de acogida.

Otro tema de debate en torno a la mediación intercultural es respecto a si la procedencia o adscripción étnica del mediador debería ser decisiva para su contratación; es decir, si debería pertenecer, obligatoriamente, a la comunidad minoritaria en la que debe intervenir. En este sentido, la mayoría de los entrevistados afirman que así lo creen (por proximidad, conocimiento interiorizado de la cultura, dominio de la lengua de origen, etc.) (EEHV10II, AMAMT10II, NMAMV10II). Su interculturalidad y su capacidad para usarla son vistas como condición fundamental de un mediador intercultural, que contaría con un estatus de experto que no comparte ningún otro agente social. Un mediador, cualquiera que sea su condición (hombre o mujer, autóctono o inmigrante, de primera o segunda generación, procedente de un matrimonio mixto o que haya vivido y trabajado en el extranjero), además de la confianza de la que se beneficia dentro de una comunidad de inmigrantes y de su neutralidad, debe haber experimentado la interculturalidad personalmente. Las experiencias interculturales y/o las propias experiencias de aculturación le llevan a construir una identidad culturalmente mestiza, producto de negociaciones anteriores y exteriores, tanto consigo mismo como con su entorno familiar y social. Este proceso se considera importante para que se pueda realizar una correcta mediación intercultural.

Otros entrevistados (ENEMB10, AMAMLL10) matizan lo anterior señalando que la contratación también debería depender de la procedencia de los destinatarios, definida por los mismos mediante binomios opuestos: ciudad-campo o árabe-imazighen. La clave diferenciadora no sería etnocultural sino socioeconómica. Las ciudades están sometidas a un importante proceso de transformación social bajo el influjo de la modernización de las relaciones de trabajo y de las condiciones de vida; en cambio, las zonas rurales mantienen buena parte de las estructuras tradicionales de producción y de relación social.

\section{Mediación nATURAL fRENTE A MEdiación PROFESIONAL}

Las entrevistadas recuerdan que, ya en sus comunidades de origen, había personas que en mayor o menor medida practicaban la mediación espontánea y natural4:

"En África valoramos siempre a las personas mayores por su experiencia, es un referente $[. .$.$] yo, cuando tengo un conflicto 0$ algo así, vengo a hablar con ella para ver qué me aconseja" (ABFMG10).

\footnotetext{
${ }^{4}$ Las grabaciones y transcripciones de las entrevistas estarán a disposicion de los investigadores que nos las soliciten.
} 
En la sociedad de acogida, tanto los responsables de la Administración como los representantes de las asociaciones de inmigrantes de origen africano también afirman que las redes informales funcionan mejor que otros mecanismos formales, al menos según su experiencia (EEHV09). De hecho, este es el canal que usan la mayor parte de los inmigrantes para encontrar alojamiento, trabajo, etc., pues los servicios institucionales les sirven de poco para ese propósito. El camino que se sigue es el siguiente: al llegar a España acuden, en primer lugar, a los amigos y familiares o a otras vías que su red social próxima les proporciona a través del boca a boca, y, en último lugar, van a las entidades comunitarias (aunque no siempre).

En efecto, lo primero que hacen es contar con los amigos que emigraron hace tiempo y que conocen los circuitos de la sociedad de acogida. Hay una extendida conciencia de auxilio, de solidaridad interna, que obliga a acoger a los recién llegados (EEMC10, NMAMV10II). Luego estos son acompañados a los servicios sociales por voluntarios, familiares, amigos o gente de las asociaciones de inmigrantes que se encargan de atender sus necesidades de mediación, traducción e interpretación. Es decir, se recurre a gente voluntariosa pero sin formación y, en ocasiones, se utiliza también al personal (médico, administrativo, etc.) de origen extranjero para llevar a cabo estas tareas. En general se hace de forma altruista pero también se han detectado casos de representantes de asociaciones africanas que cobran por sus servicios. Para ello, se sirven de cierto control en el conocimiento de los trámites administrativos (permisos de trabajo), de las redes establecidas (alquileres de vivienda), de la lengua de la sociedad de acogida o de otras facultades, como su adscripción a una entidad formal (sindicato 0 asociación, por ejemplo) (EEHC10).

\section{MÁs ALLÁ de LA TRADUCCIÓN}

La mayoría de los entrevistados critican que, antes, la Administración cogía a cualquier individuo por el mero hecho de saber el idioma del país de origen del colectivo, y su trabajo consistía, simplemente, en actuar como apagafuegos (NMAMV10II, AMAUHV10).

Por su propia experiencia y los resultados obtenidos, los mediadores desdeñan la pura traducción lingüística (AMAMB10), que es, según su opinión, lo único que la Administración tiene en cuenta: los problemas de comunicación se reducen al idioma y se resuelven con traductores, lo cual a los mediadores les parece una aberración puesto que, en la mayoría de las ocasiones, lo que se precisa son intérpretes culturales, más que lingüísticos, que ayuden a comprender el punto de vista del otro y a favorecer, así, el diálogo, la negociación y la toma de decisiones. No obstante, la mayoría de mediadores entiende que la traducción forma parte de sus atribuciones aunque con la parte negativa de que restringe su imagen a la de un actor con participación muy puntual. Si esto fuese así, los latinoamericanos no tendrían el problema del idioma pero, como señala la siguiente entrevistada, entran en juego distintos códigos culturales: 
"Sí que es verdad que hay diferencias, quizás, en la barrera del idioma, en ese sentido, sí. Pero también es cierto que el colectivo latinoamericano, si hay algo que me ha sorprendido en mi labor diaria, es que aunque hablamos el mismo idioma, muchas veces tienen dificultades a la hora de comprender, o a lo mejor lo que tienen aquí tiene una connotación cultural allí tiene otra" (ENEMN10I).

La postura y el movimiento del cuerpo, los gestos, la expresión del rostro y de la mirada, las sensaciones táctiles y olfativas son otros tantos vehículos para la comunicación no verbal de emociones y de información que hay que descubrir (NMAMV10II). Los mediadores no solo conocen las reglas de lo implícito y de lo explícito que comprende su lengua, y lo que no hay que decir según las situaciones, sino que además saben utilizar, en el idioma local o en el suyo propio, una imaginería muy gráfica, rica en metáforas, proverbios, alegorías y con múltiples referencias a la tradición y a la experiencia vivida, concreta, de los individuos (AGAMB10).

\section{DEMANDAS DE MEDIACIÓN EN LAS ASOCIACIONES DE INMIGRANTES AFRICANOS}

La mayoría de las demandas proceden de los llegados de África, que acuden por el "boca a boca" a las asociaciones (AESMA10). Las peticiones más frecuentes se refieren a: alojamiento, trabajo, ayudas económicas y prestaciones sociales, intervención en malentendidos y falta de comunicación, asesoramiento sobre los recursos existentes, refuerzo y ayuda personal, acompañamiento y traducción de la burocracia administrativa, etc. Una de las solicitudes más recurrentes tiene que ver con la necesidad de alojamiento (ASEHN10) y, posteriormente, la derivación y el acompañamiento a diferentes instituciones para acceder a los servicios de la sociedad de destino (sanidad, educación, información jurídica...). También se requiere el seguimiento en el proceso de inserción laboral, tanto del usuario como del empresario (AMAMLL10); por ejemplo, uno de los programas "estrella" es el de la prospección laboral, que comprende tanto la concienciación del tejido empresarial como la mediación e intermediación laboral.

En los últimos años se han añadido demandas de ayuda psicológica por depresión: algunos inmigrantes padecen un notable nivel de estrés producido por las dificultades para incorporarse a la nueva sociedad (Achotegui 2008) y, sobrepasada su capacidad de adaptación, van a las asociaciones a descargar sus problemas. La mala imagen de sí mismos y el bajo nivel de prestigio de su colectivo en la sociedad de destino se viven como un trauma con estrés crónico y múltiple. Este asunto entra en el ámbito de lo simbólico pues, aunque la emigración suponga una mejora de las condiciones económicas, la pérdida de relevancia social es un golpe fuerte difícilmente asimilable. Piénsese, por ejemplo, como nos relata una entrevistada, cómo puede sentirse una maestra (nivel social medio-alto en su país) que termina trabajando, en la sociedad de destino, de forma precaria en el servicio doméstico (NTUMV10). Por ello algunos inmigrantes necesitan acercarse a asociaciones, sobre todo religiosas, aunque no 
todos sean creyentes, para conseguir una cierta seguridad. La religión parece ser el centro de la vida cotidiana de la mayor parte de los inmigrantes (para ampliar, ver Mata 2013):

\begin{abstract}
"Entonces, su interés al llegar aquí es encontrar a otras personas, sobre todo vinculadas no solo a la cultura, sino yo creo que a la religión, y yo creo que también es un ejercicio de autoprotección, lo de buscar la semejanza, la seguridad, se vinculan a un centro islámico. Incluso personas que no son altamente creyentes, a su llegada, encuentran una cierta seguridad o un cierto apoyo en esa estructura que es la única que es un símil. $\mathrm{Y}$, de hecho, parece que cuando llegan aquí se vuelven más confesionales que cuando estaban allá (...) es que sí es cierto que hay centros islámicos que están detectando la necesidad de relacionarse y abrirse a la comunidad y que están creando espacios para la participación y la convivencia con otro tipo de entidades" (ADEMV10).
\end{abstract}

Como anécdota curiosa, el representante de una asociación cuenta que viajó hasta Marruecos para entregar una carta al rey Mohamed VI en la que se le pedía su mediación y ayuda económica para construir una mezquita que no estuviera ubicada en el terreno del polígono que le cedía el ayuntamiento de su ciudad (AMAHLL10), puesto que veía que era una de las demandas de los musulmanes más creyentes, que no siempre podían acudir a rezar a las afueras de la ciudad.

\title{
Principales Ámbitos de intervención. Educación y SANIDAd
}

Las intervenciones que nos describen la mayoría de entrevistados se centran, básicamente, en dos ámbitos: el educativo y el sanitario.

En el ámbito educativo observamos una mayor penetración de los mediadores en la educación formal, es decir, en escuelas e institutos, más que en la educación no formal (ver el estudio en la Comunidad Valenciana realizado por Martínez Usarralde 2007). Se trata, en la mayoría de los casos, de mediación preventiva realizada a petición de la Administración Educativa para organizar y participar en actividades culturales, cuentos, juegos, charlas, exposiciones y, sobre todo, talleres tal como relata la siguiente entrevistada:

"Vamos a hacer unas fiestecitas, que vienen los africanos así vestidos de colorines, que vienen los marroquís con sus pastelitos y té, y de ahí, se está una mañana o una tarde, y se termina" (NARMA10).

Con la participación en las actividades culturales organizadas en los centros educativos, los inmigrantes pretenden que la difusión de sus raíces favorezca la convivencia intercultural, aunque algunos lamentan que el esfuerzo se queda, a menudo, en una práctica folklórica y superficial. En este sentido, varias mediadoras catalanas de instituto comentan 
que han participado en talleres antirrumores para luchar contra los estereotipos relacionados con la inmigración que impregnan ciertos discursos de la calle (AMAHLL10).

El resto de demandas conllevan la mediación rehabilitadora para resolver determinados conflictos de valores: pañuelo islámico, carne de cerdo, la henna, actividades extraescolares, ciertas asignaturas (como la educación física, plástica y música), etc.

La utilización del velo islámico, el hiyab, ha sido causa de confrontación entre los centros educativos, la Administración Pública y las familias musulmanas (ver Ahmed 2011). Algunas entrevistadas (NMAMA10) explican que hay musulmanas que se rigen por las normas del Islam, según las cuales hay que cubrirse la cabeza después de la primera menstruación. Las más jóvenes, sin embargo, reconocen que no siempre son motivos religiosos los que las impulsan a ponerse el velo, especialmente fuera de los países árabes, sino que lo usan como manera de reafirmar su cultura, sin que tenga que ver necesariamente con las convicciones religiosas (AMAMB09). Cuando van a la playa 0 a la piscina les resulta más complicado. Aducen que el Islam no solo dicta que las mujeres deben tapar su cuerpo, sino que tampoco deberían ver a gente desnuda o semidesnuda, que es como se bañan, en playas y piscinas, la mayor parte de los occidentales. Algunas explican que han ido con la familia a alguna playa apartada, mientras que otra comenta que ella lo que hace es bañarse en las noches de verano, cuando no hay nadie: "me baño con mi pañuelo y mi chilaba, y después me cambio de ropa y ya está" (AMAMT10).

Respecto a los problemas de llevar hiyab en las clases de educación física, como el hecho de soportar altas temperaturas, tener que sujetarlo con el imperdible, etc., las entrevistadas argumentan (AMAMB10) que la asignatura sí se puede realizar si se cambian de pañuelo y, en lugar de imperdible, se lo anudan.

En relación con este tema, una de las asociaciones islámicas entrevistadas presentó ante el Tribunal Superior de Justicia de Cataluña un recurso contencioso administrativo contra la ordenanza del ayuntamiento de su ciudad que prohibía el uso del velo integral islámico, principalmente el burka y el niqab, en edificios públicos. Fundamentaron el recurso en una lesión de los derechos fundamentales y sostuvieron que la prohibición no se debía a motivos de seguridad o de convivencia, sino que se trataba de una medida discriminatoria con trasfondo religioso (AMAHLL10). La ordenanza, que se aprobó en octubre de 2010, prohíbe acceder o permanecer en edificios y equipamientos municipales a las personas que lleven velo integral, pasamontañas, casco integral u otras vestimentas o accesorios que impidan o dificulten la identificación y la comunicación visual de las personas. Las multas para los infractores oscilarían entre los 30 y los 600 euros.

En cuanto al Ramadán, hay años en que coincide con el período escolar y, aunque los menores no tienen la obligación de hacerlo, hay alumnos que empiezan a practicarlo en la educación secundaria obligatoria, con las consecuencias que ello conlleva: no duermen lo suficiente, su rendimiento se ve afectado negativamente y hasta pueden excusarse de hacer educación física. Para fomentar que hagan la clase de deporte, algunas mediadoras entrevistadas (NMAMLL10) sugieren que se permita a los alumnos estar en espacios con sombra, adaptar y reducir la intensidad del ejercicio, proponer roles distintos (por ejemplo: ejercer de árbitros), etc. 
Las mediadoras también actúan para que haya un equilibrio entre la emancipación de la mujer y el mantenimiento de vínculos con el medio familiar, como en el caso de las chicas que desean proseguir sus estudios o que rechazan el matrimonio impuesto por sus progenitores. Además, se registran problemas de absentismo, desescolarización y abandono escolar, especialmente entre el género femenino. Con el objetivo final de lograr que estas familias se involucren en el éxito escolar de sus hijos, las mediadoras hacen un seguimiento de los niños y se interesan por la inserción laboral de los jóvenes (AMAHG10I, EEHV10II, AMAHG10I).

Otra cuestión en la que inciden es la mejora de la participación y la relación de las familias en la vida escolar (ver Garreta y Llevot 2011), ya sea pidiendo su participación en las asociaciones de padres y madres de alumnos o en el consejo escolar, ya sea promoviendo su asistencia a reuniones y tutorías (AMAMB10). Su experiencia como inmigrantes les hace detectar aspectos muy concretos de la vida familiar que comportan problemas de adaptación, como la preparación, por parte de la madre, de la ropa que sus hijos llevarán el día siguiente para ir a la escuela o la rápida disposición de un desayuno suficiente antes de que salgan para la escuela.

Por otra parte, la labor que desempeñan los mediadores en el ámbito sanitario, aunque tenga menor repercusión, se centra especialmente en la traducción lingüística para facilitar la comunicación entre pacientes y profesionales de la sociedad de acogida:

"Tenemos mediación en los centros sanitarios, porque llega un señor ruso, le tienen que explicar que se tiene que operar y no lo entiende, porque el médico solo sabe decírselo en castellano, pues va alguna de nuestras mediadoras que hable ruso para intentar un poco mediar entre los dos" (EEMA10I).

Además, los mediadores intervienen cuando se producen ciertos choques culturales relacionados, entre otros, con el rol y el estatus de la mujer, la separación de géneros, la noción de tiempo, los conceptos de cuerpo, salud y enfermedad, y las prescripciones de la religión para la vida privada (ver Camilleri y Cohen-Emerique 1989; Rodríguez Cala y Llevot 2011). Los problemas más citados por nuestras entrevistadas están relacionados con la religión, el género, el tiempo, la clitoridectomía y la infibulación:

- En cuanto a la religión, los principales problemas se dan en la época del Ramadán ya que algunos alumnos no se fían de que la comida no contenga cerdo y no desean ingerirla ni tomar medicamentos durante el día.

- En relación con el género femenino, hay dos situaciones habituales: por un lado, tanto las mujeres musulmanas como sus maridos prefieren que las atienda una mujer, especialmente si hay exploración física; y, por otro lado, a veces ocultan enfermedades en el trabajo para no dar ocasión al empleador de que las despida. Si, además, el contrato laboral está supeditado a la renovación de sus permisos de residencia, apenas piden permiso para ir al médico. 
- La noción de tiempo es mucho más "elástica" en los colectivos minoritarios. En este sentido, los mediadores apuntan que se nota en la puntualidad en las citas y en que los inmigrantes no entienden que cinco minutos arriba o abajo en las consultas es un tiempo muy importante.

- Un punto candente es la clitoridectomía y la infibulación, dos prácticas que, paradójicamente, tienen que ver con la higiene pues las personas que se someten a ellas están consideradas como "personas limpias". En términos culturales y sociales, la circuncisión, tanto femenina como masculina, forma parte del rito de paso que permite a los niños el acceso al mundo de los adultos; es una marca que llevan de por vida y simboliza la pertenencia y la aceptación en el grupo. Cabe decir que la circuncisión femenina es una sunna, es decir, que pertenece a la tradición y, por lo tanto, no es un mandato del Corán. Normalmente la ablación la realizan mujeres mayores con experiencia y para ello utilizan un vidrio, una cuchilla oxidada o cualquier otro instrumento cortante, sin ninguna medida higiénica o de precaución. A estas mujeres se les retribuye con dinero 0 bienes y tienen un rango importante dentro de su clan (AGAMB10). Las razones que aducen las propias mujeres para continuar practicando operaciones de mutilación genital son de carácter práctico (la higiene, la estética, facilitar el parto, promover una cohesión social, prevenir la promiscuidad, aumentar las oportunidades matrimoniales, preservar la virginidad, mantener alejada a la mujer de los hombres, potenciar la fertilidad, mantener una buena salud y prevenir el nacimiento de niños muertos en las primerizas, ya que creen que si, al nacer, el niño toca con su cabeza el clítoris, puede morir o padecer un trastorno mental). Dicen que no se pueden beber ni ingerir alimentos que hayan sido manipulados por una solima (mujer no circuncidada), ya que se trata de una "persona impura" y, a través de este estado de impureza, ejerce una acción contaminante, especialmente en todo lo que toca:

"Porque se cree que una buena musulmana tiene que mutilarse. Una mujer, para limpiarla, se le quita el clítoris, no está dentro del Corán que haya que mutilar a las mujeres, pero esto ahora está reconocido, pero antes todas las mujeres musulmanas teníamos la creencia de que había que mutilar a las niñas, y mujeres" (AGAMB10).

Sin embargo, estas prácticas comportan una serie de efectos perjudiciales para la salud sexual y reproductiva de las mujeres, con complicaciones médicas, psicológicas y en el mantenimiento de relaciones sexuales (NMAMA10). En Cataluña, los Mossos d'Esquadra trabajan para evitar que la mutilación genital de las niñas y adolescentes no se lleve a cabo ni aquí, ni en sus países de origen, ya que algunas familias aprovechan los viajes que realizan en vacaciones, por ejemplo, para llevarse a sus hijas y así poder realizar la ablación con toda impunidad. A modo de acción preventiva de los Mossos, los policías se adelantan a estos viajes cuando creen que existe riesgo para las meno- 
res e instan a los padres a firmar un compromiso que permitirá que, a su vuelta, estas jóvenes sean exploradas por personal médico para certificar que no se ha realizado la mutilación. En el caso de que sí se hubiese realizado, los padres serían procesados. Si el riesgo es considerado muy grave, se impide que la menor viaje y se puede, incluso, retirar temporalmente la custodia a los padres. La tercera opción es de tipo pedagógico: se entrega a los padres una carta recordándoles que la ablación es un delito en nuestro país para que, cuando viajen a sus países, puedan presentarla como justificante a quien sea oportuno y evitar que se lleve a cabo la mutilación genital (esta opción no es muy efectiva puesto que la prohibición poco les importa a las autoridades religiosas del país 0 a la familia, pues no viven en España).

"Gracias al protocolo, que estipula que es un delito hacer una mutilación a una menor, está penalizado, si te pillan, es cárcel de 6 a 14 años. La gente se ha calmado y ya no se atreve a realizar la mutilación aquí, y también hemos conseguido que las niñas que han nacido aquí, cuando van a África, se le hace una revisión a la niña y los dos padres tienen que firmar un papel que no le van a hacer la mutilación. Que tienen que ir y volver sanas" (AGAMB10).

\section{El PAPEL DEL MEDIADOR EN LOS PROCESOS DE MEDIACIÓN}

La mediación que se lleva a cabo en las asociaciones es una "mediación a la carta" para los profesionales e instituciones pues estos solicitan su intervención para cuestiones muy puntuales y limitadas: traducciones, pequeñas consultas sobre la cultura del otro, ayuda para desbloquear la resistencia de algún usuario, llevar avisos, etc., y, siempre está "al servicio" del profesional.

En general, la actividad profesional de los mediadores de las asociaciones se desarrolla de la siguiente forma: ponen sus conocimientos, competencias, actitudes y habilidades a disposición de las administraciones y de la comunidad en general para facilitar la comunicación, la relación y la convivencia. El mediador intenta recabar la mayor información posible de cada una de las partes acerca de cómo perciben la situación (de conflicto o no) en la que se le pide que intervenga y cómo se sitúan en ella.

Según nos relatan, una de las diferencias que se dan (ADEMB10) entre los mediadores y los profesionales de la sociedad de acogida es que los primeros manifiestan gran preocupación por no desacreditar nunca a los protagonistas de los conflictos y lo hacen por distintas vías. Al principio de su intervención nunca ponen juntos a los protagonistas del conflicto, lo cual implica numerosos encuentros previos con unos y otros y una gran inversión de tiempo; no abordan el problema desde el inicio de la entrevista y, cuando lo hacen, evitan las maneras abruptas o minimizan la gravedad de la situación. Esto raras veces lo hacen los profesionales debido a su deseo de eficacia y de transparencia en la comunicación y por eso ponen a menudo frente a frente a las partes, como padres e hijos, ignorando ese valor fundamental en muchas sociedades tradicionales que es el 
respeto a la dignidad. Además, en la medida de lo posible, el mediador exige tratar un problema con toda la extensa familia presente en el país de acogida, y algunas veces incluso con la que se queda en el país de origen, concierta encuentros colaterales, ascendentes y descendentes, y encamina a los interesados a considerar juntos el problema. En cambio, el profesional autóctono suele trabajar con la familia nuclear y, a veces, únicamente con la madre. Este enfoque da seguridad a los inmigrantes procedentes de ámbitos tradicionales, que prefieren acudir a los mediadores pues perciben las intervenciones de otros agentes como una fuente de ruptura de las familias, ya que rápidamente colocan a los hijos en centros o familias de acogida que no tienen su misma cultura o denuncian ante el juez a un padre que corrige a su hijo con castigos corporales (NMAMA10).

El espacio de las asociaciones es un espacio neutral y es habitual que sea preferido al domicilio de la familia o a la oficina del profesional. Al final, las protagonistas intentan sellar los consensos de manera visible: estrechando la mano, firmando un acuerdo, etc. Cada vez más se tiende a organizar todo el proceso estableciendo un protocolo para registrar el seguimiento de todos los casos (AESMA10). También es cierto que los interlocutores menos formados desvirtúan, a menudo, el concepto de mediación intercultural considerándola, simplemente, como una conversación entre los suyos. Tal como relata una entrevistada:

"Desde la asociación... comenzamos haciendo una charla donde contábamos nuestros problemas con los vecinos y, a partir de aquí, conjuntamente, buscamos una solución" (ABFMG10).

Puntualmente, en alguna asociación (AMAMB10) se intenta conseguir una metodología dinámica y participativa en la que el propio usuario sea el actor principal de su proceso de inserción, y que adquiera, por el camino, competencias y habilidades imprescindibles para llegar a la autonomía necesaria aplicable a todos los ámbitos de la vida cotidiana.

En general, observamos que se están dando, y a veces confundiendo, dos grandes clases o niveles de mediación en la acción social con la población inmigrante:

- La "mediación ayuda", que sirve para facilitar el acceso de los inmigrantes a los servicios: informar, traducir, acompañar, etc., y que consiste en facilitar la comunicación y comprensión entre personas; pero en esta dinámica no cambia nada la manera de intervenir, solo es una ayuda para un futuro usuario de las políticas sociales relacionadas con la nueva situación de inmigración.

- La mediación que apunta a una "participación crítica", que es la que abarca las tres modalidades de Cohen-Emerique (2011). Es la mediación que acerca a las partes para que puedan comunicarse y construir acuerdos, y entren en un auténtico proceso de negociación. Apuesta, pues, por un mestizaje mutuamente enriquecedor. 
En general, todas las asociaciones han declarado tener dificultades para garantizar los recursos físicos y humanos que requiere el mantenimiento de toda estructura asociativa, así como el de las actuaciones mediadoras. De hecho, la mayoría de las asociaciones dependen para su funcionamiento del voluntariado y, además, carecen de un lugar propio y estable. Esto está relacionado, evidentemente, con las vías de financiación a las que acceden y con las posibilidades reales que tienen para garantizar los recursos económicos necesarios para su funcionamiento. A estas dificultades hay que añadir la resistencia a la figura del mediador por parte de los profesionales, que temen que aquéllos invadan sus competencias aunque, en este sentido, los entrevistados afirman que, con frecuencia, se les utiliza para hacer recados o traducir a usuarios extranjeros sin sacarles todo el beneficio que pueden aportar. Es decir, su reconocimiento profesional es aún escaso.

\section{LA FORMACIÓN INICIAL Y LA FORMACIÓN CONTINUA EN LA MEDIACIÓN}

La mayoría de los entrevistados (y se da el caso de que son todos presidentes de asociaciones) han realizado cursos de formación inicial en mediación intercultural con profesionales independientes dedicados a diseñar e impartir cursos en organismos públicos y afirman que esta formación les ha llevado a crear su propia asociación. En los últimos años algunas universidades se han sumado a esta labor formativa ya que, desde diversos departamentos o institutos, ofrecen postgrados y másteres específicos en mediación.

Los entrevistados nos indican cómo los pioneros, y otros que les han seguido en este tipo de iniciativas, han podido desarrollar su actividad gracias a la concesión de subvenciones públicas y/o privadas y a su participación en proyectos europeos transnacionales, y que esto ha potenciado el desarrollo de las asociaciones; además, aseguran que el alumnado lo ha percibido como una futura salida laboral.

La trayectoria formativa de los mediadores es diversa; algunos, por ejemplo, empezaron con un curso de mediación de unas pocas horas que les sirvió para conseguir un empleo:

"El curso de mediador fue en el 99-2000. Le puse mucho interés y voluntad. Antes de empezar el curso ya estuve, porque aparte nos hicieron unos test, un dictado y comentario de texto. Y me cogieron" (ASEHA10).

Después continuaron formándose: una parte de ellos siguió con otros estudios (grados, másteres e, incluso, tesis doctorales) y pretende seguir investigando en este campo, por ello se abren a la vía que ofrece la mediación (NTUMV10, ENEMN10I, EEMA10l); mientras que otros se han ido quedando en formaciones puntuales, hecho que dificulta su inserción o continuidad laboral (ver Llevot 2011).

Los más formados son los que han "evolucionado" de la mediación natural a la profesional, y los que asumen que deben tener una competencia profesional para ejercer su tarea; es decir, que quieren estar formados en temas de inmigración e interculturalidad, comunicación intercultural, interpretación lingüística y sociocultural, negociación y 
mediación para la prevención y gestión de conflictos culturales en diversos ámbitos de intervención (justicia, servicios sociales, salud, educación, vivienda, inserción laboral, dinamización comunitaria, etc.) y, sobre todo, tener títulos reconocidos. Pero, en general, se acusa la falta de una formación reglada y homologada, reconocida, de referencia y con prestigio social como profesionales (EEHV09).

\section{LAS CONDICIONES LABORALES DE LOS MEDIADORES}

La mayoría de los mediadores entrevistados (por no decir todos) y los profesionales que trabajan con ellos confiesan que se encuentran en una difícil situación laboral (inestabilidad en la contratación, jornada y salario), independientemente de si tienen un diploma o certificado. Suelen tener contratos temporales de obra o servicio y, en algunos ayuntamientos, antes de la crisis económica, se habían empezado a convocar oposiciones para su contratación indefinida. En las asociaciones, las contrataciones van ligadas en su mayor parte a programas subvencionados con fondos de la Administración y, por tanto, la temporalidad en la contratación y la precariedad laboral es más acusada. Esta situación de inestabilidad o temporalidad laboral lleva a que muchos programas duren menos de un año.

Otro aspecto señalado es que la mediación presenta las características de una nueva profesión, con lo que se observa en el ámbito institucional una gran desorientación y también falta de unidad entre los practicantes de este oficio, ya que en general, ejercen en condiciones laborales eventuales y precarias, lo cual hace muy difícil que puedan sobrevivir solo con ello (AMAMT10II).

La precariedad económica (aparte de honorarios bajos, que no les cubren las facturas de móvil, desplazamientos, etc.) afecta a la continuidad, y este hecho imposibilita que se vean los resultados de la mediación a largo plazo, que reflejen realmente una transformación de las partes encontradas (AMAHG10I). Ante la necesidad de subsistencia, la mayoría de los entrevistados compatibilizan la mediación con otros trabajos, más o menos relacionados con ella (NARMA10).

La crisis actual ha supuesto el recorte de los programas y las subvenciones en general y, concretamente, de las destinadas a la mediación (NTUMV10, NMMV10), hecho que aún precariza más la situación laboral de los mediadores.

\section{Algunas Conclusiones a tener en CUENTA}

A la luz de lo expuesto, podemos afirmar que se están utilizando las dos formas básicas de mediación: espontánea y profesional. La acción mediadora natural, por lo que hemos visto, solo se produce esporádicamente o queda circunscrita a un determinado círculo de amistades 0 de relaciones familiares que operan como traductores o mensajeros, 0 a las personas que, por la antigüedad de su asentamiento, pueden ayudar dentro del mencionado círculo a gestionar los vínculos institucionales, brindando informaciones y acompañamientos, y facilitando la inclusión social del inmigrante al ofrecerle vivienda y trabajo. 
Las asociaciones de inmigrantes realizan múltiples papeles, son diversas en su organización y tienen capacidad para materializarlos. Los inmigrantes se dirigen a las asociaciones para pedir asesoramiento o ayudas de tipo social: ayudas de urgencia, vivienda, educación, documentación, clases de español, etc., ya que no entienden el funcionamiento de la sociedad de acogida. Los resultados del estudio apuntan a que se trata de espacios de convivencia y de relación entre los asociados y con los que no lo están. La mediación pretende: facilitar la inserción, crear vínculos y redes sociales, mediar en conflictos cuando estos se producen (aunque no sigan un protocolo específico), sensibilizar a la población mayoritaria, etc., y es una de las actividades más frecuentes entre las asociaciones encuestadas.

Una problemática concreta de la mediación intercultural en las asociaciones es la "semiprofesionalización". La precariedad laboral y la contratación inestable que se desprenden de esta realidad obligan a que las personas que ejercen este trabajo en el entorno asociativo tengan que complementar esta dedicación con otros trabajos remunerados. La dificultad radica en que no se está dando un reconocimiento profesional del mediador, ni de su ámbito de actuación. En la práctica, ni profesionales, ni entidades, ni instituciones, están reconociendo efectivamente su importancia, por desconocimiento, a veces, o por sensación de amenaza, otras.

El mediador, hoy por hoy, no tiene unos estudios específicos que lo vinculen a su ejercicio profesional de una manera especializada. Esta realidad se atribuye tanto a los mediadores interculturales de las asociaciones como a los institucionales, siendo el error más flagrante el primer caso, ya que los mediadores de las asociaciones no han de acreditarse a través de un concurso público. Las orientaciones de las ayudas públicas al ámbito cultural han sido mencionadas como la clave para comprobar mejor qué actividades se potencian en las asociaciones y cuáles no. En los ayuntamientos o servicios de gobiernos autonómicos que tienen contratados a mediadores se viene dando con demasiada frecuencia una "domesticación" de esta figura. Las entrevistas y cuestionarios muestran que las asociaciones se ven empujadas a dirigir sus actividades al ámbito cultural, debido al tipo de subvenciones promovidas por las instituciones. Así, la mediación y el codesarrollo responden en gran medida a la presión del entorno.

Pese a la variedad de mediaciones y mediadores interculturales de las asociaciones, los entrevistados las presentan como indispensables para la integración. Con la mediación se pretende crear una dinámica social positiva que no solo evitaría la exclusión, sino que abriría la vía al respeto a la diversidad cultural. Para los agentes sociales estas experiencias de mediación modifican su percepción de las familias y les hacen descubrir otro enfoque de intervención, fuente de apertura, de enriquecimiento y de satisfacción profesional frente a estos grupos de población. Todo lo cual provocará que las actuaciones de las instituciones con personas de culturas diferentes sean más adecuadas a su realidad.

El mediador puede proponer actuaciones innovadoras que tengan como resultado modificar las instituciones, como implica el tercer tipo de mediación (creativa), aunque no tenga ningún poder de decisión; de ahí la importancia de la intervención de las asociaciones de mediadores ante los servicios institucionales para abrir camino a los cambios. 
El modelo que se va imponiendo es el de profesionales de la mediación que trabajan en proyectos o servicios dirigidos y gestionados por entidades públicas o privadas, las cuales se dedican a muchas otras cosas, además de a la acción socioeducativa con inmigrantes. Se intenta trabajar en determinados lugares con una cierta independencia de los mediadores respecto a otros profesionales, lo que constituye uno de los temas centrales de la mediación que se realiza actualmente.

Sin embargo, algunas reflexiones realizadas con las personas entrevistadas apuntan hacia un autocuestionamiento, en parte de estas asociaciones, respecto a la línea de acción principal que debe llevar el colectivo, en el sentido de que deberían ampliar su horizonte más allá de los ámbitos social y cultural, pensar más allá del propio origen cultural y crear redes entre todas las personas inmigrantes. De ahí que sea también necesario analizar, en un futuro, cómo y en qué medida las asociaciones están influyendo y participando activamente en los procesos de toma de decisiones sobre las cuestiones que afectan al colectivo pero también habrá que atender a aquello que afecta al desarrollo de su vida cotidiana y a la convivencia con la sociedad receptora.

\section{REFERENCIAS BIBLIOGRÁFICAS}

Abdallah-Pretceille, M. 1986. Vers une pédagogie interculturelle. París: Anthropos.

Achotegui, J. 2008. "Migración y Crisis: el síndrome del inmigrante con estrés crónico y múltiple (síndrome de Ulises)." Avances en Salud Mental Relacional 7:1-28.

AEP Desenvolupament Comunitari/Andalucía Acoge. 2002. Mediación intercultural. Una propuesta para la formación. Madrid: Popular.

Ahmed, L. 2011. A quiet revolution. The veil's resurgence, from the Middle East to America. New Heaven and Londres: Yale University Press.

Camilleri, C., y M. Cohen-Emerique. 1989. Chocs de cultures: Concepts et enjeux pratiques de l'interculturel. Collection "Espaces interculturels." París: L'Harmattan.

Cohen-Emerique, M. 1999. "La negociation-mediation, phase essentialle dans l'intégration des migrants et dans la modification des attitudes des acteurs sociaux chargés de leur integration." Vie sociale. Les acteurs de l'intégration 2:139-155.

Cohen-Emerique, M. y S. Fayman. 2005. "Médiateurs interculturels, passerelles d'identité." Connexions 83:169-190.

Cohen-Emerique, M. 2011. Pour une approche interculturelle en travail social. París: Presses de l'EHESP.

Garreta, J. y N. Llevot. 2011. "Immigrant Families and the Shool in Spain: Dynamics and Factors that influence." ECPS Journal 4:47-67.

Garreta, J. y N. Llevot. 2013. "Las asociaciones de inmigrantes africanos. Organización, proyección y actuaciones" Revista Internacional de Sociología, vol. 71, Extra 1:15-38.

Jabbaz M. y A. Moncusí. 2010. "Mediación intercultural 'natural'. Reflexiones a partir de una experiencia en Orriols." Revista Migraciones 27:171-198. 
Llevot, N. 2006. "Prospectiva y retrospectiva de la mediación intercultural en Cataluña." Revista de Trabajo Social Portularia 1:29-41.

Llevot, N. 2011. "La mediación intercultural en España." Pp. 134-150 en Immigrazione e intercultural in Italia e in Spagna. Prospettive, proposte ed esperienze a confronto, coordinado por M. Fiorucci y M. Catarci. Milano: Unicoplo.

Martínez Usarralde, M. J. 2007. "Análisis comparado de las funciones educativas implícitas y explícitas de los mediadores culturales de las oficinas de Acogida al Alumnado Inmigrante en la Comunidad Valenciana." Comunicación presentada en el V Congreso sobre Inmigración en España Migraciones y desarrollo humano, 22 marzo, Valencia.

Martínez Usarralde, M. J. y R. García López. 2009. Análisis y práctica de la mediación intercultural desde criterios éticos. Valencia: Tirant Lo Blanch.

Mata, A. y J. Giró. 2013. "Reflexiones sobre la influencia de los componentes religiosos en el asociacionismo inmigrante." Revista Internacional de Sociología Vol. 71, Extra 1: 117-140.

Moncusí, A. y M. Albert. 2013. "El rol del asociacionismo de inmigrantes africanos en la construcción de cohesión social y la convivencia en Cataluña, Navarra y la Comunidad Valenciana. Miradas cruzadas." Revista Internacional de Sociología Vol. 71, Extra 1: 39-65.

Peticlerc, J. M. 2007. "La mediación social." Pp. 121-132 en Lecturas para mediación intercultural: comprendiendo y construyendo la mediación intercultural, editado por J. García Castaño. Granada: Laboratorio de estudios interculturales, Universidad de Granada.

Rodríguez Cala, A. y N. Llevot. 2011. "La mediación intercultural: una realidad en los hospitales." Pp. 1065-1073 en Actas del I Congreso Internacional sobre Migraciones en Andalucía, coordinado por J. García Castaño y N. Kressova. Granada: Instituto de Migraciones.

Richarte, I. y L. Díe. 2008. "La mediación intercultural y la puerta hacia otro mundo posible." Documentación Social 148:133-155.

Six, J. F. 1990. Le temps des médiateurs. París: Seuil.

Núria Llevot Calvet es profesora contratada doctora de pedagogía en el Departamento de Pedagogía y psicología de la Universidad de Lleida. Su trabajo investigador se ha centrado en mediación intercultural, diversidad cultural y educación y la integración de minorías étnicas. En los últimos años ha sido investigadora invitada en la Université de Montréal, Roma Tre y París 8.

JoRdi GaRRETA BochaCA es profesor titular de sociología del Departamento de Geografía y sociología de la Universidad de Lleida. Su trabajo investigador se ha centrado en sociología de la educación (escolarización del alumnado de origen extranjero, políticas de integración y participación de las familias en la escuela) y en sociología de las migraciones (movimientos migratorios, integración, participación social). En los últimos años ha sido investigador invitado en l'Université de Montréal y en l'Ecole des Hautes Études en Sciences Sociales (París).

RECIBIDO: 07/09/2012

ACEPTADO: 19/12/2012

Publicado on-line: 27/05/2013 